\title{
Evaluation of prostate cancer prevalence in Iranian male population with increased PSA level, a one center experience
}

This article was published in the following Dove Press journal:

Cancer Management and Research

24 June 2011

Number of times this article has been viewed

\author{
Mohammad Kazem \\ Moslemi' \\ Fariborz Lotfi ${ }^{2}$ \\ Seyed Ali Tahvildar ${ }^{3}$ \\ 'Department of Urology, Kamkar \\ Hospital, School of Medicine, Qom \\ University of Medical Sciences, Qom, \\ Iran; ${ }^{2}$ School of Medicine, Kermanshah \\ University of Medical Sciences, \\ Kermanshah, Iran; ${ }^{3}$ Department of \\ Urology, School of Medicine, Islamic \\ Azad University, Qom Branch, Qom, Iran
}

Correspondence: Fariborz Lotfi School of Medicine, Kermanshah University of Medical Sciences, Kermanshah, 1494883 I I3, Iran Tel +98 912 197 7|3| Email dr.f.lotfi@gmail.com
Purpose: This study was conducted to evaluate the incidence of prostate cancer ( $\mathrm{PCa}$ ) in Iranian male patients with increased prostate-specific antigen (PSA), and normal or abnormal digital rectal examination (DRE) that underwent prostate biopsy.

Materials and methods: From March 2006 to April 2009, a total of 346 consecutive males suspected of having PCa due to increased PSA levels underwent transrectal ultrasonography (TRUS)-guided sextant biopsy of the prostate. The total PSA (tPSA), demographic data, incidence of $\mathrm{PCa}$, benign prostate hyperplasia (BPH), and prostatitis were assessed.

Results: The patients were divided into two groups according to their PSA values (group A serum tPSA level, 4-10 ng/mL; group B serum tPSA level, 10.1-20.0 ng/mL). Of the 346 biopsied cases, 193 cases $(56 \%)$ had PCa, 80 cases $(23 \%)$ had BPH, and 73 cases $(21 \%)$ had prostatitis. The mean PSA and the age of the carcinoma group were significantly higher than those of the benign group $(P<0.01)$. The biopsy results were grouped as $\mathrm{PCa}, \mathrm{BPH}$, and prostatitis. Incidence of PCa for group A and group B cases were 115 cases (51\%), and 78 cases (65\%), respectively. In the case of $\mathrm{PCa}, \mathrm{BPH}$, and prostatitis, the mean PSAs were $10.02 \mathrm{ng} / \mathrm{mL}, 8.76 \mathrm{ng} / \mathrm{mL}$, and $8.41 \mathrm{ng} / \mathrm{mL}$, respectively $(P<0.40)$.

Conclusion: TRUS-guided prostate biopsy and interpretation by a skilled team is highly recommended for early detection of PCa or its ruling-out. It seems that a PSA cutoff value of $4 \mathrm{ng} / \mathrm{mL}$ may be applied to the Iranian population. Although the chance of PCa is high in the PSA levels of 4-10 ng/mL, the combination of some data, like age and prostate volume, can decrease the rate of unnecessary prostate biopsies. We recommend prostate biopsy when PSA and/or DRE is elevated in symptomatic patients with obstructive and/or irritative lower urinary tract symptoms (LUTS) such as dysuria, frequency, or nocturia. Due to the very high incidence of PCa in the patients with PSA greater than $10 \mathrm{ng} / \mathrm{mL}$, TRUS-guided biopsy is indicated, whatever the findings on DRE and/or LUTS, since the PCa detection rate is high.

Keywords: prostate-specific antigen, benign prostate hyperplasia, $\mathrm{BPH}$, prostate biopsy, prostate carcinoma, PCa, digital rectal examination, DRE, lower urinary tract symptoms, LUTS

\section{Introduction}

Prostate cancer $(\mathrm{PCa})$ is one of the most common cancers in the male population and is the second leading cause of cancer death for men in the USA. ${ }^{1}$ It is a major cause of morbidity and mortality in Iran, ${ }^{2}$ yet there are few studies determining the relation between prostate-specific antigen (PSA) levels and the risk of PCa. The mortality of $\mathrm{PCa}$ on the basis of geographic area differs. In the Scandinavian area and southern Europe its prevalence is high, and in eastern Asia its prevalence is the least. Its prevalence is directly related to age. PSA and digital rectal examination (DRE) are 
good screening tools of PCa. In this retrospective study, we evaluated PCa prevalence in Iranian male patients that were referred to our center for transrectal prostate biopsy due to increased PSA level.

Unfortunately, in Iran, most PCa is already associated with nonorgan-confined disease or bone metastasis at detection. Therefore, focusing research on methods of its early detection has developed. ${ }^{2}$

PSA is secreted by the epithelial cells lining the acini and the ducts of the prostate gland in both normal and malignant conditions., ${ }^{3,4}$ The serum levels of PSA are elevated in PCa and benign prostate hyperplasia (BPH)., ${ }^{3,5,6}$ Prostate biopsy has been usually performed in clinical practice in cases with increased PSA levels. Although a serum PSA level of $4.0 \mathrm{ng} / \mathrm{mL}$ is used as a cutoff point for PCa screening, it is relatively difficult to differentiate prostate adenocarcinoma from benign prostatic hyperplasia $(\mathrm{BPH})$ in patients with gray-zone PSA levels (4-10 ng/mL). ${ }^{8-11}$

PCa early detection guidelines are mainly based on data from the USA and Europe and may not be relevant to other geographic areas or ethnic groups. ${ }^{12}$

This study was designed to evaluate the significance of total PSA (tPSA) in the PSA of $4-10 \mathrm{ng} / \mathrm{mL}$ and its comparison with PSA levels of 10-20 ng/mL for discrimination between benign and malignant prostate disease in Iranian men.

\section{Materials and methods}

This is a retrospective study in which Iranian males with increased PSA levels ( $4 \mathrm{ng} / \mathrm{dL}$ ) that referred to transrectal ultrasound (TRUS) prostate biopsy were evaluated. In this study, a total of 346 males with increased PSA values with or without positive DRE (4-20 ng/mL) were evaluated in the 3 consecutive years from March 2006 to April 2009. The mean age of these patients was 65.81 years, ranging from 45 to 87 years, with standard deviation (SD) of 8.50 . Of these, $39(11.3 \%)$ were $<55$ years old, $68(19.7 \%)$ were between 56 and 60 years old, 136 (39.3\%) were between 61 and 70 years old, 52 (15\%) were between 71 and 75 years old, and $51(14.7 \%)$ were $>76$ years old (Table 1$)$. This study was

Table I Age distribution of eligible cases

\begin{tabular}{ll}
\hline Age, years & n (\%) \\
\hline$<55$ & $39(11.3 \%)$ \\
$56-60$ & $68(19.7 \%)$ \\
$61-70$ & $136(39.3 \%)$ \\
$71-75$ & $52(15 \%)$ \\
$>76$ & $51(14.7 \%)$ \\
\hline
\end{tabular}

performed in Bistoon Uroradiology Private Clinic, Tehran, Iran. Prior to DRE, tPSA were measured for all of these patients. None of them had current urinary tract infections, clinical prostatitis, and history of prior prostate surgery (transurethral resection of the prostate or open prostatectomy). A sextant biopsy was performed from the apex and base of the right and left parasagittal planes of the prostate with 10 core biopsies. If hypoechoic areas were noted on TRUS, a specimen was taken from each of these areas.

Demographic data including age, PSA level, prostate volume, and pathology result were evaluated. PSA was measured by using the Tandem-R assay. Prostate volume was calculated by using the following formula:

$$
\Pi / 6 \times \mathrm{L} \times \mathrm{W} \times \mathrm{H}
$$

where $\mathrm{L}=$ length, $\mathrm{W}=$ width, and $\mathrm{H}=$ height. The patients were divided into two groups: group A, with PSA level between 4 and $10 \mathrm{ng} / \mathrm{dL}$; and group B, with PSA level between 10 and $20 \mathrm{ng} / \mathrm{dL}$. On the basis of prostate weight, the mean, median, $\mathrm{SD}$, and variance was $56.48 \mathrm{~cm}^{3}, 49 \mathrm{~cm}^{3}$, 27.34, and 747.94, respectively.

The total number in group A was 226 (65.3\%), and group B was 120 (34.7\%) (Tables 2 and 3). One experienced pathologist performed the histopathological examinations. Atypical small acinar proliferation and prostate intraepithelial neoplasia were excluded from the study. Demographic and clinical characteristics of patients with and without prostate adenocarcinoma were compared with the use of statistical t-test.

This study was conducted in accordance with the Declaration of Helsinki. The local medical ethical committee approved the study.

TRUS-guided, systematic, sextant, six-core biopsies with two additional biopsies from transition zone were done using a biopsy gun (Promag 1, MD Tech, Gainesville, FL) with an 18-gauge biopsy needle (2.2 Biopsy Needle, MD Tech). ${ }^{13}$ The histological criteria for PCa used were those of the World Health Organization. ${ }^{13,14}$ Cancers were graded according to the Gleason grading system. ${ }^{15}$

Table 2 Characteristics of group A and group B

\begin{tabular}{lll}
\hline Characteristic & Group A & Group B \\
\hline PSA, ng/mL & $4-10$ & $10-20$ \\
Mean age, years & 64.38 & 68.5 \\
Number of cases (\%) & $226(65.3 \%)$ & $120(34.7 \%)$ \\
\hline
\end{tabular}

Abbreviation: PSA, prostate-specific antigen. 
Table 3 Histopathology of biopsied cases

\begin{tabular}{|c|c|c|c|c|c|}
\hline \multirow[t]{2}{*}{ Group } & \multirow{2}{*}{$\begin{array}{l}\text { Mean } \\
\text { age (SD) }\end{array}$} & \multirow[t]{2}{*}{$\mathbf{N}$} & \multicolumn{3}{|l|}{ n (\%) } \\
\hline & & & $\mathrm{PCa}$ & BPH & Prostatitis \\
\hline Group A & $64.4(8.13)$ & 226 & II 5 (5I\%) & 59 (26\%) & $52(23 \%)$ \\
\hline Group B & $68.5(8.5)$ & 120 & $78(65 \%)$ & 21 (17.5\%) & $21(17.5 \%)$ \\
\hline
\end{tabular}

Abbreviations: $\mathrm{BPH}$, benign prostate hyperplasia; $\mathrm{PCa}$, prostate cancer; $\mathrm{SD}$, standard deviation.

\section{Statistical analysis}

The statistical analysis of the collected data were performed using SPSS Statistics, version 16.0 (SPSS Inc, Chicago, IL) software. ${ }^{16}$ The values of continuous variables were demonstrated as mean \pm standard deviation. Comparisons of variables (age, prostate volume, PSA, and pathologic diagnosis) were done with the $t$-test. $P$-values less than 0.05 were considered significant.

\section{Results}

The overall final pathologic diagnosis was prostate adenocarcinoma in 193 cases (56\%), BPH in 80 cases (23\%), and prostatitis - subacute or chronic - in 73 cases (21\%). The group specific pathologic diagnosis was as follows: for group A, prostate adenocarcinoma in 115 cases (51\%), BPH in 59 cases $(26 \%)$, and prostatitis - subacute or chronic - in 52 cases (23\%) (Table 3); for group B, prostate adenocarcinoma in 78 cases $(65 \%)$, BPH in 21 cases $(17.5 \%)$, and prostatitis - subacute or chronic - in 21 cases $(17.5 \%)$ (Table 3).

The mean (and SD) for age of group A and group B were, 64.38 years (8.134) and 68.5 years (8.56), respectively (Table 3).

The mean (and SD) prostate volume for group A and group B were $55 \mathrm{~cm}^{3}$ (23.963) and $59.5 \mathrm{~cm}^{3}$ (32.702), respectively. The mean prostate volume for $\mathrm{PCa}$ cases was $46.09 \mathrm{~cm}^{3}$. The mean prostate volume for prostatitis cases was $64.67 \mathrm{~cm}^{3}$, with SD of 26.304. The mean prostate volume for BPH cases was $74.06 \mathrm{~cm}^{3}$, with SD of 33.51 (Table 4).

Table 4 The relations between the pathologic diagnoses, age, PSA, and prostate volume

\begin{tabular}{llll}
\hline & $\begin{array}{l}\text { Mean age } \\
(\text { SD) }\end{array}$ & $\begin{array}{l}\text { Mean PSA } \\
(\text { SD) }\end{array}$ & $\begin{array}{l}\text { Prostate } \\
\text { volume }^{\mathbf{b}}\end{array}$ \\
\hline PCa & $67.6(8.9)$ & $10.02(4.37)$ & $46 \mathrm{~cm}^{3}$ \\
BPH & $64.5(7.5)$ & $8.4(3.56)$ & $74 \mathrm{~cm}^{3}$ \\
Prostatitis & $62.3(6.8)$ & $8.7(3.72)$ & $64.67 \mathrm{~cm}^{3}$
\end{tabular}

Notes: ${ }^{a} P=0.01 ; b P=0.4 ; c P=0.01$.

Abbreviations: $\mathrm{BPH}$, benign prostate hyperplasia; $\mathrm{PCa}$, prostate cancer; PSA, prostate-specific antigen; SD, standard deviation.
The mean PSA level for PCa was $10.02 \mathrm{ng} / \mathrm{dL}$, with SD of 4.37. The mean PSA level for prostatitis was $8.76 \mathrm{ng} / \mathrm{dL}$, with SD of 3.72. The mean PSA level for BPH was $8.41 \mathrm{ng} / \mathrm{dL}$, with SD of 3.56 .

The mean (and SD) age for $\mathrm{PCa}$, prostatitis, and $\mathrm{BPH}$ were 67.63 years (8.98), 62.34 years (6.83), and 64.58 years (7.52), respectively (Table 4).

The mean Gleason score for group A was 6.5 and for group B was $6.7(P \leq 0.05)$.

The statistical relation between the PSA level and $\mathrm{PCa}$ was significant $(P<0.40)$.

ANOVA test was used for the determination of the relation between the age and $\mathrm{PCa}$; and it was significant $(P<0.01)$. With this test, the relation between PCa and BPH was significant $(P<0.01)$. The relation between age and PSA was significant $(P>0.01)$. Based on our study, the positive predictive value for $\mathrm{PCa}$ in group A was $51 \%$ and for group B, $65 \%$.

Age was correlated positively with tPSA in both the $\mathrm{PCa}$ group and the BPH group in all tPSA ranges $(0.001)$. This means that in our cases, the proportion of males with PSA levels above the cutoff value increased with age.

The mean PSA value (range, SD) in all men with $\mathrm{PCa}$ was $10 \mathrm{ng} / \mathrm{mL}$ (4-20 $\mathrm{ng} / \mathrm{mL}, 4.37)$, in those with BPH was $8.4 \mathrm{ng} / \mathrm{mL}$ (4-20 ng/mL, 3.56), and in those with prostatitis was $8.7 \mathrm{ng} / \mathrm{mL}(4-20,3.72) \mathrm{ng} / \mathrm{mL}(P<0.001)$ (Table 4$)$.

\section{Discussion}

The incidence of PCa in Iran is significantly less than those in developed countries, and similar to eastern Mediterranean regions ${ }^{17} \mathrm{PCa}$ is the most frequently reported malignancy in Iranian males after stomach cancer. ${ }^{18,19}$ Among genitourinary cancers, it is the second most common cancer after bladder cancer, with an incidence of $33.4 \%{ }^{20}$ The lowest recorded PCa rate is 0.4 per 100000 in Ardabil, northwest Iran. ${ }^{13,21}$ Iranian men are ethnically and racially different from most of Asian men, ${ }^{22}$ so the biochemical parameters of PCa should be different. In a study by Khezri et $\mathrm{al}^{23}$ in a large Iranian healthy male population, the serum PSA concentration correlated directly with the subject's age and prostatic volume. Based on this study, the age-related PSA cutoff point was $2.61 \mathrm{ng} / \mathrm{mL}$ for $50-59$ years, $3.59 \mathrm{ng} / \mathrm{mL}$ for $60-69$ years, and $4.83 \mathrm{ng} / \mathrm{mL}$ for $70-79$ years. The serum PSA levels and prostate volume are age- and race-dependent. For this reason, we chose the cutoff point of $4 \mathrm{ng} / \mathrm{mL}$ for prostate biopsy. In another study by Mehrabi et al, the PSA cutoff level in the males older than 69 years is $4.4 \mathrm{ng} / \mathrm{mL}{ }^{24}$ 
In our study, of 346 patients with serum PSA levels between 4 and $20 \mathrm{ng} / \mathrm{mL}$, only $56 \%$ had pathologically diagnosed PCa, which is much lower than values used in Western countries. This can be explained by a widely different geographical prevalence of $\mathrm{PCa} .{ }^{25}$ Amirrasouli et $\mathrm{al}^{25}$ evaluated 332 Iranian men with serum tPSA levels of 4-20 ng/mL. After TRUS prostate biopsy, they detected PCa in $15 \%$ of their patients. Incidence of PCa for serum tPSA level $10 \mathrm{ng} / \mathrm{mL}$ and serum tPSA level of $10.1-20.0 \mathrm{ng} / \mathrm{mL}$ was $6.7 \%$ and $39.5 \%$, respectively. Catalona et al, ${ }^{26}$ found positive findings on prostate biopsy in less than $50 \%$ of the patients with PSA of 4-10 ng/mL.

Several studies showed an advantage of using PSAD compared with tPSA alone. ${ }^{11,12,27-30}$ Lam et $\mathrm{al}^{31}$ recommended a PSAD cutoff of $0.15 \mathrm{ng} / \mathrm{mL}$ for detection of PCa, which spared half of the patients from undergoing unnecessary biopsies. In spite of its value, we did not consider the role of PSAD in this study.

Although several studies showed that PSA screening had a beneficial effect, the results of the selected studies were inconsistent, and mass screening is not warranted. ${ }^{32,33}$ Both PSA and DRE were not recommended for populationbased screening programs, but they could be conducted individually. ${ }^{32}$

Hua et $\mathrm{al}^{34}$ studied the prostate biopsy results in 295 Chinese cases with PSA levels $\geq 4 \mathrm{ng} / \mathrm{mL}$; the positive detection rate of $\mathrm{PCa}$ was $19.7 \%$. In our Iranian cases, the positive detection rate was $56 \%$.

We observed, like Gohji et al, ${ }^{35}$ in the patients with PCa, the prostate volume was smaller, and the age was higher than in the patients with BPH or prostatitis.

In the Safarinejad study, ${ }^{13}$ the detection rate of $\mathrm{PCa}$ in Iranian males using PSA alone was reported at 3.5\%, which reflects an increase in its incidence. In addition, Safarinejad detected $17.5 \%$ PCa in cases with PSA 4-10 ng/mL, and $47.6 \%$ in cases with PSA $10-20 \mathrm{ng} / \mathrm{mL}$.

\section{Conclusion}

Comparing our study results with others, we found that PSA alone can be used efficiently as a first and/or repeat test for PCa screening of Iranian males. In addition, we found that the chance of $\mathrm{PCa}$ increases with increasing age, lesser weight of prostate, and increased tPSA. There was no difference in the Gleason score in our two groups of different PSA levels (4-10 and 10-20 ng/mL).

\section{Disclosure}

The authors report no conflicts of interest in this work.

\section{References}

1. Howe HL, Wingo PA, Thun MJ, et al. Annual report to the nation on the status of cancer (1973 through 1998), featuring cancers with recent increasing trends. J Natl Cancer Cancer Inst. 2001;93: 824-842.

2. Hosseini M, Seyed Alinaghi S, Ahmoudi M, McFarland W. A casecontrol study of risk factors for prostate cancer in Iran. Acta Med Iran. 2010;48(1):61-66.

3. Stamey TA, Yang N, Hay AR, McNeal JE, Freiha FS, Redwine E. Prostate-specific antigen as a serum marker for adenocarcinoma of the prostae. N Engl J Med. 1987;317:909-916.

4. Lin K, Lipsitz R, Miller T, Janakiraman S. Benefits and harms of prostate-specific antigen screening for prostate cancer: an evidence update for the US Preventive Services Task Force. Ann Intern Med. 2008;149(3):192-199.

5. Oesterling JE. Prostate specific antigen: a critical assessment of the most useful tumor marker for adenocarcinoma of the prostate. J Urol. 1991;145:907-923.

6. Moslemi MK, Abedin Zadeh MA. A modified technique of simple suprapubic prostatechomy: no bladder drainage and no bladder neck or hemostatic surfaces. Urol J. 2010;7(1):51-55.

7. Benson MC, Whang IS, Pantuck A, et al. Prostate specific antigen density: a means of distinguishing benign prostatic hypertrophy and prostate cancer. J Urol. 1992;147:815-816.

8. Catalona WJ, Richie JP, Ahmann FR, et al. Comparison of digital rectal examination and serum prostate specific antigen in the early detection of prostate cancer: results of a multicenter clinical trial of 6,630 men. J Urol. 1994;151:1283-1290.

9. Park HK, Hong SK, Byun SS, Lee SE. Comparison of the rate of detecting prostate cancer and the pathologic characteristics of the patients with a serum PSA level in the range of 3.0 to $4.0 \mathrm{ng} / \mathrm{mL}$ and the patients with a serum PSA level in the range 4.1 to $10.0 \mathrm{ng} / \mathrm{mL}$. Korean J Urol. 2006;47:358-361.

10. Cho JM, Lee SW, Kang JY, Yoo TK. Safety and efficacy of combined transrectal ultrasound-guided prostate needle biopsy and transurethral resection of the prostate. Korean J Urol. 2010;51(2):101-105.

11. Rommel FM, Agusta VE, Breslin JA, et al. The use of prostate specific antigen and prostate specific antigen density in the diagnosis of prostate cancer in a community based urology practice. J Urol. 1994; 151:88-93.

12. Dadkhah F, Safarinejad MR, Amini E, Lashay AR, Baghayee A. Utility of prostate specific antigen density and free to total prostate specific antigen ratio for detecting prostate cancer in Iranian men: a prospective study of 187 cases. Curr Urol. 2010;4:1-5.

13. Hosseini SY, Moharramzadeh M, Ghadian AR, Hooshyar H, Lashay AR, Safarinejad MR. Population-based screening for prostate cancer by measuring total serum prostate-specific antigen in Iran. Int $J$ Urol. 2007; 14:406-411.

14. Mostofi FK, Sesterhenn I, Sobin LH. Histological typing of prostate tumors. In: Mostofi FK. International Histological Classification of Tumors No. 22. Geneva: World Health Organization; 1980: $1-26$.

15. Gleason DF. Veterans Administration Cooperative Urological Research Group. Histologic grading and staging of prostatic carcinoma. In: Tannenbaum M, editor. Urologic Pathology: the prostate. Philadelphia: Lea \& Febiger; 1977:171-198.

16. Ghafoori M, Varedi P, Hosseini SJ, Asgari M, Shakiba M. Value of prostate-specific antigen and prostate-specific antigen density in detection of prostate cancer in an Iranian population of men. Urol J. 2009;6(3):182-188.

17. Mousavi SM. Toward prostate cancer early detection in Iran. Asian Pac J Cancer Prev. 2009;10(3):413-418.

18. Mohagheghi MA, Mosavi-Jarrahi R, Malekzadeh R, Parkin M. Cancer incidence in Tehran metropolis: the first report from the Tehran Population-based Cancer Registry, 1998-2001. Arch Iran Med. 2009; 12(1):15-23. 
19. Mousavi SM, Gouya MM, Ramazani R, Davanlou M, Hajsadeghi N, Seddighi Z. Cancer incidence and mortality in Iran. Ann Oncol. 2009; 20(3):556-563.

20. Akbari ME, Hosseini SJ, Rezaee A, Hosseini MM, Rezaee I, Sheikhvatan M. Incidence of genitourinary cancers in the Islamic Republic of Iran: a survey in 2005. Asian Pac J Cancer Prev. 2008;9(4): 549-552.

21. Sadjadi A, Malekzadeh R, Derakhshan MH, et al. Cancer occurrence in Ardabil. Results of a population-based cancer registry from Iran. Int J Cancer. 2003;107:113-118.

22. Safarinejad MR. Population-based screening for prostate cancer by measuring free and total serum prostate-specific antigen in Iran. Ann Oncol. 2006;17:1166-1171.

23. Khezri AA, Shirazi M, Ayatollahi SM, et al. Age specific reference levels of serum prostate-specific antigen, prostate volume and prostate specific antigen density in healthy Iranian men. Iran J Immunol. 2009; 6(1):40-48.

24. Mehrabi S, Ghafarian Shirazi H, Rasti M, Bayat B. Analysis of serum prostate-specific antigen levels in men aged 40 years and older in Yasuj, Iran. Urol J. 2005;2:189-192.

25. Amirrasouli H, Kazerouni F, Sanadizade J, et al. Accurate cut-off point for free to total prostate-specific antigen ratio used to improve differentiation of prostate cancer from benign prostate hyperplasia in Iranian population. Urol J. 2010;10;7(2):99-104.

26. Catalona WJ, Partin AW, Slawin KM, et al. Use of the percentage of free prostate-specific antigen to enhance differentiation of prostate cancer from benign prostatic disease: a prospective multicenter clinical trial. JAMA. 1998;279:1542-1547.

27. Kang SH, Bae JH, Park HS, et al. Prostate-specific antigen adjusted for the transition zone volume as a second screening test: a prospective study of 248 cases. Int J Urol. 2006;13:910-914.
28. Yamamoto S, Kin U, Nakamura K, et al. Transperineal ultrasoundguided 12-core systematic biopsy of the prostate for patients with a prostate specific antigen level of 2.5-20 ng/mL in Japan. Int J Clin Oncol. 2005; 10:117-121.

29. Okihara K, Kitamura K, Okada K, Mikami K, Ukimura O, Miki T. Ten year trend in prostate cancer screening with high prostate specific antigen exposure rate in Japan. Int J Urol. 2008;15:156-160.

30. Sheikh M, Al-Saeed O, Kehinde EO, Sinan, Anim JT, Ali Y. Utility of volume adjusted prostate specific antigen density in the diagnosis of prostate cancer in Arab men. Int Urol Nephrol. 2005;37:721-726.

31. Lam JS, Cheung YK, Benson MC, Goluboff ET. Comparison of the predictive accuracy of serum prostate specific antigen levels and prostate specific antigen density in the detection of prostate cancer in HispanicAmerican and white men. J Urol. 2003;170:451-456.

32. Hamashima C, Nakayama T, Sagawa M, Saito H, Sobue T. The Japanese guidelines for prostate cancer screening. Jpn J Clin Oncol. 2009;39(6) 339-351.

33. van Vugt HA, Bangma $\mathrm{CH}$, Roobol MJ. Should prostate-specific antigen screening be offered to asymptomatic men? Expert Rev Anticancer Ther. 2010;10(7):1043-1053.

34. Hua LX, Qiao D, Song NH, et al. Clinical value of prostate specific antigen screening in early detection of prostate cancer. Zhonghua Zhong Liu Za Zhi. 2009;31(9):705-709.

35. Gohji K, Nomi M, Egawa S, et al. Detection of prostate carcinoma using prostate specific antigen, its density, and the density of the transition zone in Japanese men with intermediate serum prostate specific antigen concentrations. Cancer. 1997;79(10):1969-1976.
Cancer Management and Research

\section{Publish your work in this journal}

Cancer Management and Research is an international, peer-reviewed open access journal focusing on cancer research and the optimal use of preventative and integrated treatment interventions to achieve improved outcomes, enhanced survival and quality of life for the cancer patient The journal welcomes original research, clinical \& epidemiological

\section{Dovepress}

studies, reviews \& evaluations, guidelines, expert opinion \& commentary, case reports \& extended reports. The manuscript management system is completely online and includes a very quick and fair peerreview system, which is all easy to use. Visit http://www.dovepress.com/ testimonials.php to read real quotes from published authors. 